\title{
In vivo analysis of hip joint loading on Nordic walking novices
}

\author{
Yannick Palmowski ${ }^{1}$ (B), Srdan Popovic ${ }^{2}$, Simone G. Schuster ${ }^{2}$, Sebastian Hardt ${ }^{1}$ and Philipp Damm²*
}

\begin{abstract}
Objective: To evaluate the influence of Nordic walking (NW) on hip joint loads in order to determine whether it can be safely performed during postoperative physiotherapy in patients after orthopeadic surgery of the hip.

Methods: Internal hip joint loads were directly measured in vivo in 6 patients using instrumented hip prostheses during NW and ordinary walking (OW). All patients received training in two different NW techniques (double-poling and the diagonal technique) by a certified NW instructor. Measurements were conducted on a treadmill at a speed of $4 \mathrm{~km} / \mathrm{h}$ on level ground, at 10\% inclination and at 10\% slope as well as on a level lawn at a self chosen comfortable speed. Resultant contact force $\left(F_{\text {res }}\right)$, bending moment $\left(M_{\text {bend }}\right)$ and torsional torque $\left(M_{\text {tors }}\right)$ were compared between NW and OW as well as between both NW techniques.
\end{abstract}

Results: Joint loads showed a double peak pattern during all setups. Neither NW technique significantly influenced hip joint loads at the time of the first load peak during contralateral toe-off (CTO), which was also the absolute load peak, in comparison to OW. Compared to OW, double-poling significantly reduced $F_{\text {res }}$ and $M_{\text {bend }}$ at the time of the second load peak during the contralateral heel strike (CHS) on level ground both on the treadmill $(-6 \%$ and $-7 \%$, respectively) and on the lawn ( $-7 \%$ and $-9 \%)$. At $10 \%$ inclination, the diagonal technique increased $F_{\text {res }}$ and $M_{\text {bend }}$ at CHS (by $+6 \%$ and $+7 \%$ ), but did not increase the absolute load peak at CTO.

Conclusion: Joint loads during NW are comparable to those of OW. Therefore, NW can be considered a low-impact activity and seems to be safe for patients that are allowed full weight bearing, e.g. during postoperative rehabilitation after THA.

\section{Introduction}

Loading of the musculoskeletal system and joints plays a fundamentdal role in a wide variety of orthopaedic conditions, e.g. regarding osteoarthritis, fractures or after orthopaedic surgery [1]. Mechanical stress of the joints is regarded as an important factor contributing to the development of osteoarthritis, and excessive joint loads may increase the risk of complications such as implant failure, aseptic lossening or implant wear after arthroplasty or internal fixation of fractures [1-7].

\footnotetext{
*Correspondence: philipp.damm@charite.de

${ }^{2}$ Berlin Institute of Health at Charité - Universitätsmedizin Berlin, Julius Wolff Institute, Augustenburger Platz 1, 13353 Berlin, Germany

Full list of author information is available at the end of the article
}

Osteoarthritis of the hip joint is among the most common orthopaedic conditions and often results in the necessaity of a total hip arthroplasty (THA) for affected patients $[8,9]$. The average age of patients receiving THA surgery has been steadily decreasing during the last years and especially for younger patients, the ability to resume sports is one of the key aims after surgery [10-12]. This has lead to an increase in physical activity of the average patient after joint replacement and thereby also to higher functional demands of the THA [13, 14]. However, there are no evidence based guidelines regarding the return to sports after such surgery, and recommendations regarding the adequate amount and type of physical activity diverge $[10,15]$. While excessive sport might lead to accelerated wear, loosening or even fractures, a certain

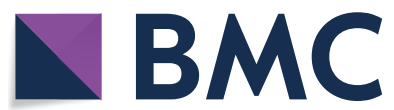

(c) The Author(s) 2021. Open Access This article is licensed under a Creative Commons Attribution 4.0 International License, which permits use, sharing, adaptation, distribution and reproduction in any medium or format, as long as you give appropriate credit to the original author(s) and the source, provide a link to the Creative Commons licence, and indicate if changes were made. The images or other third party material in this article are included in the article's Creative Commons licence, unless indicated otherwise in a credit line to the material. If material is not included in the article's Creative Commons licence and your intended use is not permitted by statutory regulation or exceeds the permitted use, you will need to obtain permission directly from the copyright holder. To view a copy of this licence, visit http://creativecommons.org/licenses/by/4.0/. The Creative Commons Public Domain Dedication waiver (http://creativecommons.org/publicdomain/zero/1.0/) applies to the data made available in this article, unless otherwise stated in a credit line to the data. 
level of physical activity certainly improves quality of life, reduces diverse health risks (e.g. obesity) and may strengthen the muscles supporting the hip joint [16-19]. High impact sports are generally considered to bear the highest risks whereas commonly recommended activities are those that ensure a mobility of the joint, but are not suspected to cause high peak loads, such as cycling aquatic excercice, or Nordic walking (NW) [19-24]. NW has been shown to be effective as cardiovascular training, even though it doesn't cause a perceived difference in exertion rate compared to ordinary walking $[25,26]$. Despite the increase in energy consumption during NW, the ground reaction forces, which were used to calculate the acting joint loads indirectly, have even been reported to be reduced in comparison to ordinary walking as the impact disperses when the poles strike the ground [27]. Such combination of effective cardiovascular training and potentially decreased joint loads would make NW an ideal option for patients with osteoarthritis or after orthopaedic surgery like arthroplasty or fracture fixation.

However, available studies investigating the loads on the musculoskeletal system during NW came to conflicting conclusions as to whether NW increases or decreases joint loads and are all based solely on the measurement of the individual ground reaction forces using force plates or instrumented insoles [28-36]. Using such methods, internal joint loads can only be indirectly estimated through musculoskeletal models [37-40]. A novel approach to directly assess the internal forces is the use of instrumented hip implants, which are able to directly measure in vivo forces and moments in the joint [41-43]. This method has already been used successfully to evaluate other methods of hip joint reduction [21,44].

The aim of the present study was to clarify the influence of NW on hip joint loads using direct in vivo measurements and to evaluate if NW is an appropriate physical activity for patients after orthopedic surgeries of the hip. For this purpose, we used instrumented hip implants to evaluate in vivo hip joint loads during NW and to compare them to joint loads during ordinary walking. Our hypothesis was that NW does not increase hip joint loads in comparison to ordinary walking and is therefore an ideal option for postoperative physiotherapy after orthopaedic surgeries like THA.

\section{Material and methods}

\section{Instrumented implants}

An already described instrumented hip endoprosthesis was used for in vivo measurements of joint loads [43]. It allows to determine the resultant joint force components $F_{x}, F_{y}$ and $F_{z}$ as well as the moment components $M_{x}, M_{y}$ and $M_{z}$ with a possible measuring error of $1-2 \%$ [44]. These force components were subsequently used to calculate the resultant contact force $F_{\text {res }}$ acting relative to at the femoral head, the bending moment $M_{\text {bend }}$ acting in the middle of the femur neck, which quantifies most of the stress in the implant neck, as well as the torsion torque $M_{\text {tors }}$ in the bone-stem-interface respectively in femur shaft axis, which may influence the initial torsional stability of cementless implants in the femur, based on a coordinate system centered at the head of a right side implant (Fig. 1) [45].

\section{Subjects}

Six patients with an instrumented hip prosthesis were willing to participate and are included in this study (Table 1). All patients underwent hip replacement surgery using using the direct lateral approach These patients are part of a worldwide unique collective of 10 patients with instrumented implants (all of which were asked to participate in the present study) and have already participated in other previously published studies $[21,24,45-52]$. The measurements were performed between 8 and 32 months after surgery. In all patients, the indication for the THA had been osteoarthritis and all of them were NW novices.

\section{In vivo load measurements}

For all in vivo load measurements, the same NW Poles (Flash Vario $^{\circledR}$, model 2012, Leki, Kirchheim, Germany) were used. The standard length of the poles was $120 \mathrm{~cm}$, but could be individually adapted by $\pm 5 \mathrm{~cm}$ to fit the patients' proportions (Table 1).

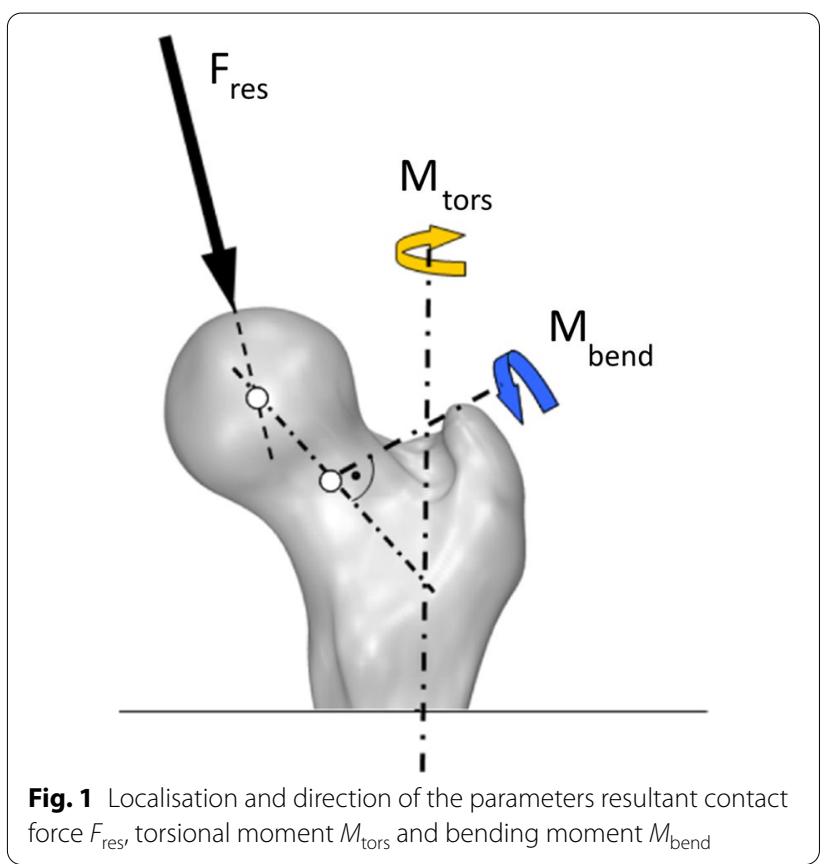


Table 1 Subjects participating

\begin{tabular}{|c|c|c|c|c|c|c|c|}
\hline Participant & Gender & Age* (years) & Weight $^{*}(\mathrm{~kg})$ & Height* $(\mathrm{cm})$ & $B M{ }^{*}\left(\mathrm{~kg} / \mathrm{m}^{2}\right)$ & $\begin{array}{l}\text { Time since } \\
\text { surgery* (months) }\end{array}$ & Pole length $(\mathrm{cm})$ \\
\hline $\mathrm{H} 2 \mathrm{R}$ & M & 64 & 80 & 172 & 27 & 32 & 118 \\
\hline $\mathrm{H} 5 \mathrm{~L}$ & W & 64 & 87 & 168 & 30.8 & 24 & 118 \\
\hline $\mathrm{H} 6 \mathrm{R}$ & M & 69 & 86 & 176 & 27.8 & 17 & 120 \\
\hline $\mathrm{H} 7 \mathrm{R}$ & M & 54 & 92 & 179 & 28.7 & 19 & 123 \\
\hline H8L & M & 56 & 86 & 178 & 27.1 & 14 & 123 \\
\hline H9L & M & 54 & 118 & 181 & 36.3 & 8 & 120 \\
\hline $\mathrm{MW} \pm \mathrm{STD}$ & & $60 \pm 6$ & $91 \pm 14$ & $176 \pm 5$ & $30 \pm 3$ & $19 \pm 8$ & $120 \pm 2$ \\
\hline
\end{tabular}

* on the day of the measurements

The in vivo load data were collected during walking and NW on a level lawn at self-chosen speed as well as during treadmill walking on level ground with $4 \mathrm{~km} / \mathrm{h}$. Furthermore, the in vivo loads were determined at ordinary walking respectively NW with $10 \%$ inclination and with $10 \%$ slope at $4 \mathrm{~km} / \mathrm{h}$. For each measurement two different NW techniques, the diagonal technique and double-poling, were performed (Fig. 2) and the resultant in vivo joint loads were examined in comparison to ordinary walking without poles.

For the diagonal technique, each arm comes forward together with the contralateral leg and the pole is put onto the ground around the same time as the contralateral heel. For the double-poling technique, both poles come forward together with the same leg and are put onto the ground at the same time, either in a 2:1 or a 3:1 rhythm. In our study, a 2:1 rhythm was performed in which the NW poles always touched the ground at the same time as the heel of the ipsilateral leg.

As none of the participants had prior experience with NW, each received an individual instruction by a licensed NW instructor before the measurements. Additionally, all measurements were performed under the guidance of the same instructor as well. Selected trials of each measurement are published and can be downloaded at the public data base www. OrthoLoad.com. After familiarization, around 30 steps were measured for each setup and patient, which were averaged first individually and then for the whole cohort.

\section{Data collection and evaluation}

During the in vivo load measurements, all patients were filmed continually and simultaneously the in vivo data from the instrumented prostheses were stored on the same ditigital video tape. Details regarding the methods

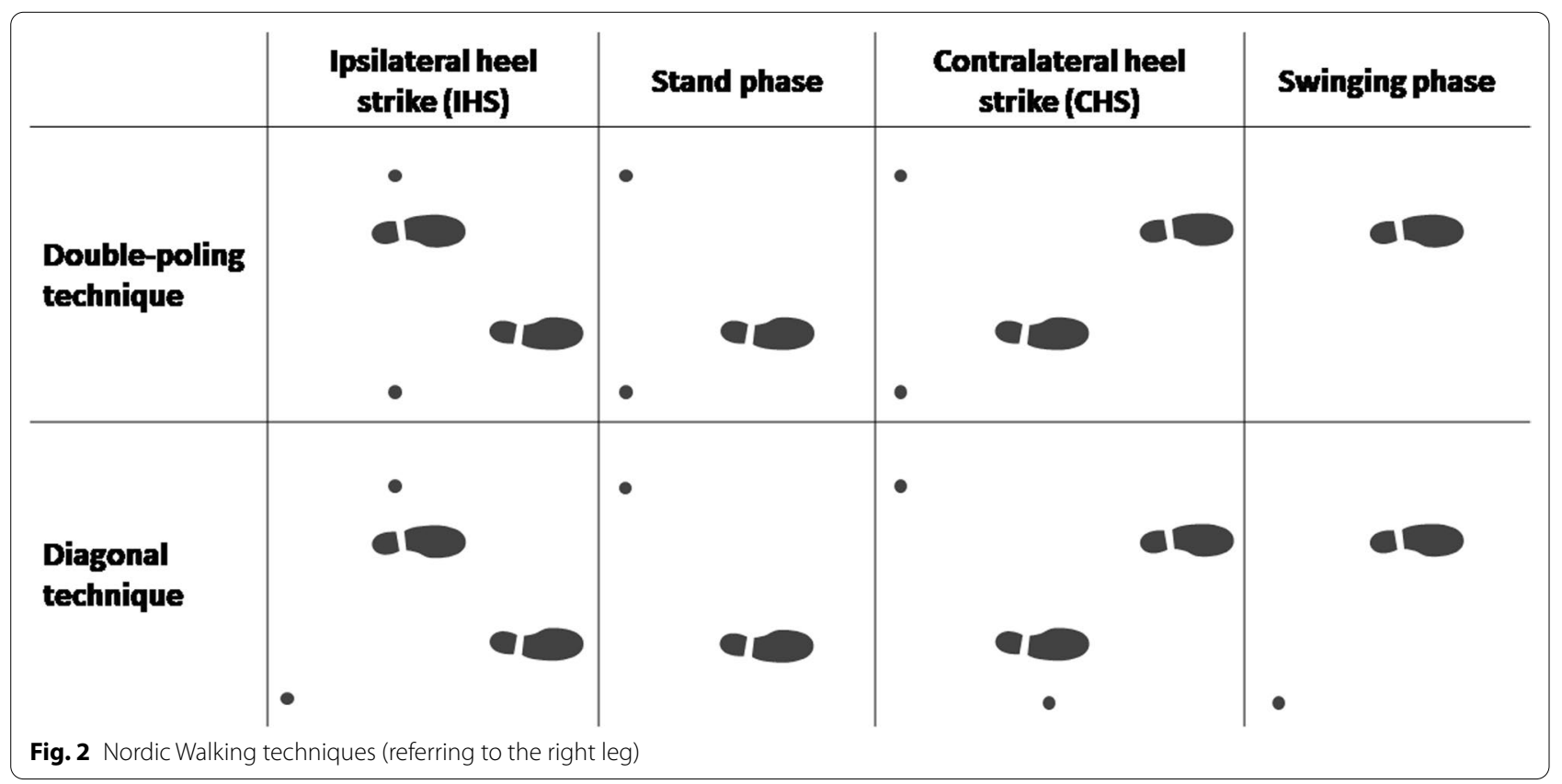


and the external measurement system have already been described previously [53].

The in vivo determined time-load patters of each patient were averaged intra-individually and separately for each walking technique using a time warping method [54]. Subsequently, an inter-individual average was calculated for each load component based on the individual averages to determine time load patterns of an average subject for each walking techniques. Peak loads at characteristic time points were determined for each load component. All in vivo measured forces and moments were given as percent of the bodyweight \%BW respectively \%BWm.

Statistical analysis was performed using IBM SPSS Statistics 20.0/21.0 (New York, USA). Non-parametric

Table 2 Walking speed during ordinary walking and Nordic walking (NW) on a lawn with two different techniques

\begin{tabular}{|c|c|c|c|}
\hline & $\begin{array}{l}\text { Ordinary walking } \\
(\mathrm{km} / \mathrm{h})\end{array}$ & $\begin{array}{l}\text { NW-diagonal } \\
(\mathrm{km} / \mathrm{h})\end{array}$ & $\begin{array}{l}\text { NW-double- } \\
\text { poling }(\mathrm{km} / \mathrm{h})\end{array}$ \\
\hline $\mathrm{H} 2 \mathrm{R}$ & 4.06 & 4.54 & 3.80 \\
\hline $\mathrm{H} 5 \mathrm{~L}$ & 4.73 & 4.60 & 4.81 \\
\hline $\mathrm{H} 6 \mathrm{R}$ & 3.71 & 4.81 & 4.79 \\
\hline $\mathrm{H} 7 \mathrm{R}$ & 4.62 & 4.75 & 4.47 \\
\hline $\mathrm{H} 8 \mathrm{~L}$ & 3.97 & 4.00 & 4.35 \\
\hline H9L & 5.04 & 5.25 & 5.55 \\
\hline Mean & 4.35 & 4.66 & 4.63 \\
\hline
\end{tabular}

Wilcoxon Test was used to compare the mean values with respect to the different setups. The significance level was set to $p \leq 0.05$.

\section{Results}

\section{Walking on a level lawn}

In the first part of the in vivo load measurement the participants walked on a level lawn with and without NW poles at a self-chosen comfortable speed (Table 2). On average, the patients walked faster when using NW poles than when walking without. The difference in walking speed between NW and ordinary walking varied interindividually between +1.1 and $-0.26 \mathrm{~km} / \mathrm{h}$.

The in vivo measured joint loads $F_{\text {res }}$ and $M_{\text {bend }}$ show a double-peaked pattern that is characteristic for walking (Fig. 3). The first maximum occurs at the time of contralateral toe-off (CTO) and is followed by a second maximum at the time of contralateral heel strike (CHS). $M_{\text {tors }}$ shows a clear maximum corresponding to the first maxima of $F_{\text {res }}$ and $M_{\text {bend }}$ at CTO. Overall the curves show similar patterns for ordinary walking and the two NW techniques.

Absolute averaged peak loads for each parameter occurred at CTO with $323 \% \mathrm{BW}$ for $F_{\text {res }}, 4.06 \% \mathrm{BWm}$ for $M_{\text {bend }}$ and $3.3 \% \mathrm{BWm}$ for $M_{\text {tors }}$, whereas joint loads at CHS were lower with $267 \% \mathrm{BW}$ for $F_{\text {res }}$ and $4.01 \% \mathrm{BWm}$ for $M_{\text {bend }}$ (values for ordinary walking). For all three examined parameters the overall highest joint loads were observed during $\mathrm{NW}$ using the diagonal technique at

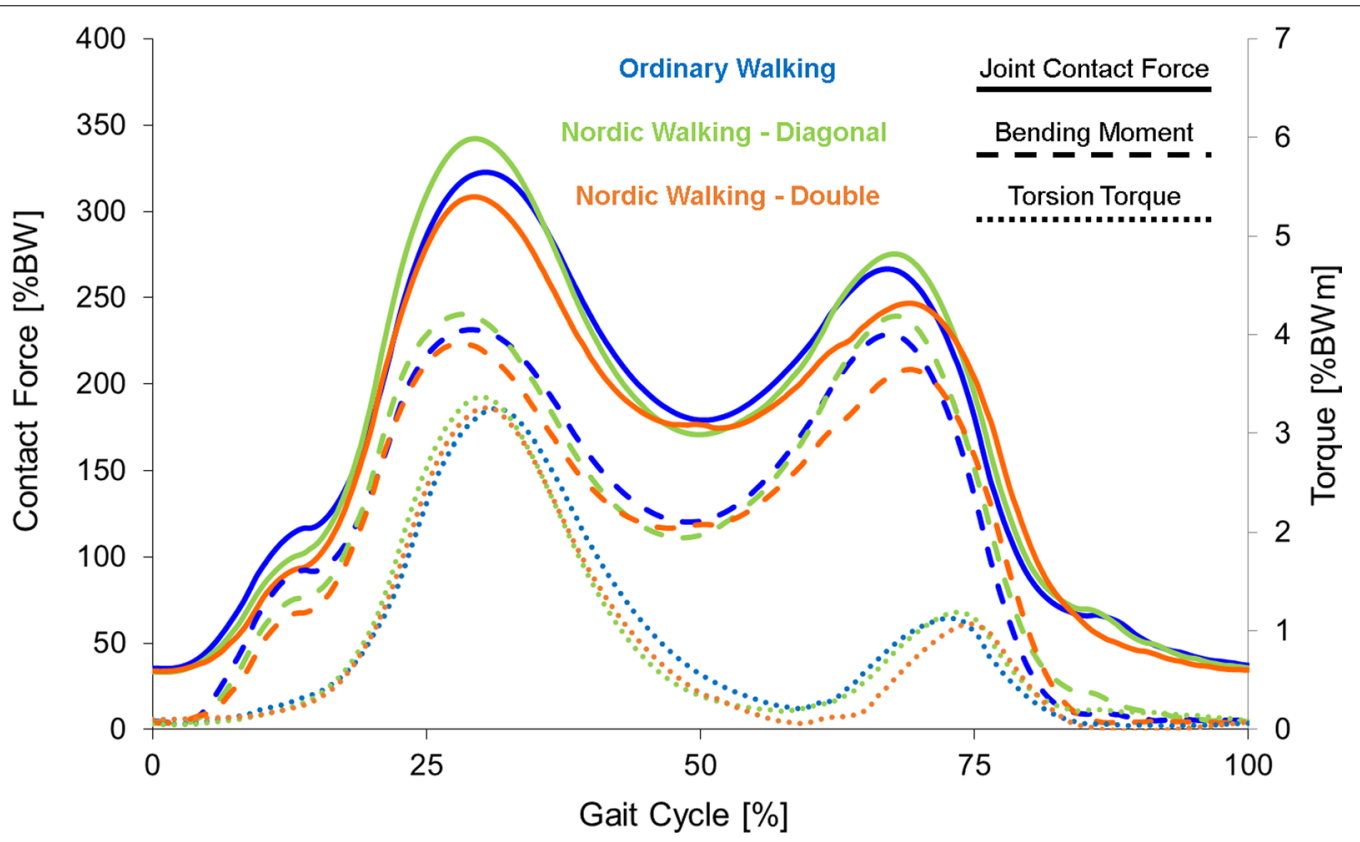

Fig. 3 Hip joint loads during walking on level lawn 
the time of contralateral toe off (CTO), with on average $343 \% \mathrm{BW}$ for $F_{\text {res }}, 4.22 \% \mathrm{BWm}$ for $M_{\text {bend }}$ and $3.44 \% \mathrm{BWm}$ for $M_{\text {tors }}$ NW with either technique did not have a significant influence on absolute peak joint loads at CTO compared to ordinary walking. Double-poling NW technique resulted in the overall lowest joint loads with $309 \% \mathrm{BW}(\mathrm{CTO})$ and $248 \% \mathrm{BW}(\mathrm{CHS})$ for $F_{\text {res }}, 3.92 \% \mathrm{BWm}$ (CTO) and 3.66\%BWm (CHS) for $M_{\text {bend }}$, and $3.32 \% \mathrm{BWm}$ for $M_{\text {tors }}$. Double-poling significantly reduced the second (lower) maxima for both $F_{\text {res }}$ and $M_{\text {bend }}$ by $-7 \%$ and $-9 \%$ compared to ordinary walking (Table 3 ). The respective first (higher) maxima showed a trend towards a load reduction for double-poling, while $M_{\text {tors }}$ does not change relevantly.

\section{Treadmill walking on level ground at $\mathbf{4} \mathbf{~ k m} / \mathbf{h}$}

For treadmill walking on level ground at $4 \mathrm{~km} / \mathrm{h}, F_{\text {res }}$ and $M_{\text {bend }}$ also show the double-peaked pattern that is characteristic for walking. The absolute peak joint loads during ordinary walking on treadmill with $4 \mathrm{~km} / \mathrm{h}$ were on average $300 \% \mathrm{BW}$ for $F_{\text {res, }}, 3.89 \% \mathrm{BWm}$ for $M_{\text {bend }}$ and $2.54 \% \mathrm{BWm}$ for $M_{\text {tors }}$ (Table 3). This equals a reduction of joint forces of $-7.1 \%$ for $F_{\text {res }},-4.2 \%$ for $M_{\text {bend }}$ and $-23 \%$ for $M_{\text {tors }}$ compared to walking on a lawn.

Overall the curves show a similar pattern for ordinary walking and the two NW techniques. Neither of the two NW techniques significantly influenced the absolute peak loads at CTO. NW using the diagonal technique shows a trend towards increased joint loads, which is most pronounced for $M_{\text {bend }}$ at CHS with $+6 \%$, but does not reach significance level (Table 3). Double-poling significantly reduces the second (lower) peak at CHS of $F_{\text {res }}$ by $-6 \%$ and $M_{\text {bend }}$ by $-7 \%$, but shows a trend towards an increase in $M_{\text {tors }}$ of $+6 \%$.

\section{Walking with inclination and slope on a treadmill at $4 \mathrm{~km} / \mathrm{h}$} Walking with inclination and slope showed the same double-peaked pattern for $F_{\text {res }}$ and $M_{\text {bend }}$ as walking on level ground, both for ordinary walking and for NW. However, the first maximum (at CTO) increased for both parameters by up to $+11.7 \%$ (ordinary walking, $F_{\text {res }}$ ) and $+10.3 \%$ (ordinary walking, $M_{\text {bend }}$ ) at a $10 \%$ slope compared to walking on a level treadmill. For all three examined parameters $\left(F_{\text {res}}, M_{\text {bend }}\right.$ and $M_{\text {tors }}$ ), the highest joint loads were observed at the time of CTO using the diagonal technique at $10 \%$ slope with $340 \% \mathrm{BW}$ for $F_{\text {res }}$, $4.29 \% \mathrm{BWm}$ for $M_{\text {bend }}$ and $3.46 \% \mathrm{BWm}$ for $M_{\text {tors }}$. NW with either technique did not significantly change absolute peak joint loads at CTO compared to ordinary walking. Using the diagonal technique at $10 \%$ inclination significantly increased the second maxima (at CHS) of both $F_{\text {res }}$ by $+6 \%$ and $M_{\text {bend }}$ by $+7 \%$, compared to ordinary walking with $10 \%$ inclination. For a slope of $10 \%$, the in vivo hip joint loads for the diagonal technique did not significantly differ from ordinary walking with the same slope. Double-poling did not significantly change any of the examined joint loads at $10 \%$ inclination or at $10 \%$ slope in comparison to ordinary walking.

\section{Comparison of joint loads between diagonal technique and double-poling (all setups)}

When comparing in vivo joint loads between both NW techniques, diagonal versus double poling, $F_{\text {res }}$ and $M_{\text {bend }}$ show a general trend towards higher values for the diagonal technique (Table 4). The highest differences were observed during walking on a level lawn, where doublepoling significantly reduced the absoluted peak of $F_{\text {res }}$ at CTO compared to the diagonal technique. Additionally, it significantly reduced $F_{\text {res }}$ at CHS by $-10 \%$ and $M_{\text {bend }}$ at CHS by $-13 \%$ on a level lawn. There were no significant differences between both techniques regarding $M_{\text {tors }}$.

\section{Discussion}

In this study we examined hip joint loads in vivo during ordinary walking and NW at different inclinations and using two different NW techniques. The aim was to clarify the influence of NW on hip joint loads and to determine in vivo whether NW is an appropriate physical activity during postoperative rehabilitation in patients after orthopaedic surgery of the hip. For this purpose, we used instrumented implants to conduct direct measurements of the respective joint loads during NW in vivo. It should be noted that this is an important difference to most existing studies we compare our data to, as the majority of them calculate internal forces from external measurement using the musculoskeletal models [28-36]. Such mathematical models may come to different results since they rely on the measurement of external instead of intrinsicly generated forces.

Regarding the influence of NW on in vivo joint loads during level treadmill walking, neither of the two NW techniques lead to a significant increase in joint loads. The double poling technique resulted in a slight but significant decrease of joint contact Force $F_{\text {res }}(-6 \%)$ as well as the bending moment $M_{\text {bend }}$ on the femur neck $(-7 \%)$ at the time of the contralateral heel strike respectively the second (lower) peak of the typical load pattern, while absolute peak loads at CTO were not significantly influenced. Similar results were observed for walking on a level lawn at self chosen velocity, where double poling also slightly, yet significantly reduced the second (lower) peak of both $F_{\text {res }}$ and $M_{\text {bend }}$ by $-7 \%$ and $-9 \%$, respectively. The diagonal technique on the other hand showed a trend towards higher joint loads of $+3 \%$ for the absolute peak loads of $F_{\text {res }}$ and $M_{\text {tors }}$, which however did not reach significance. It should be noted that the average 


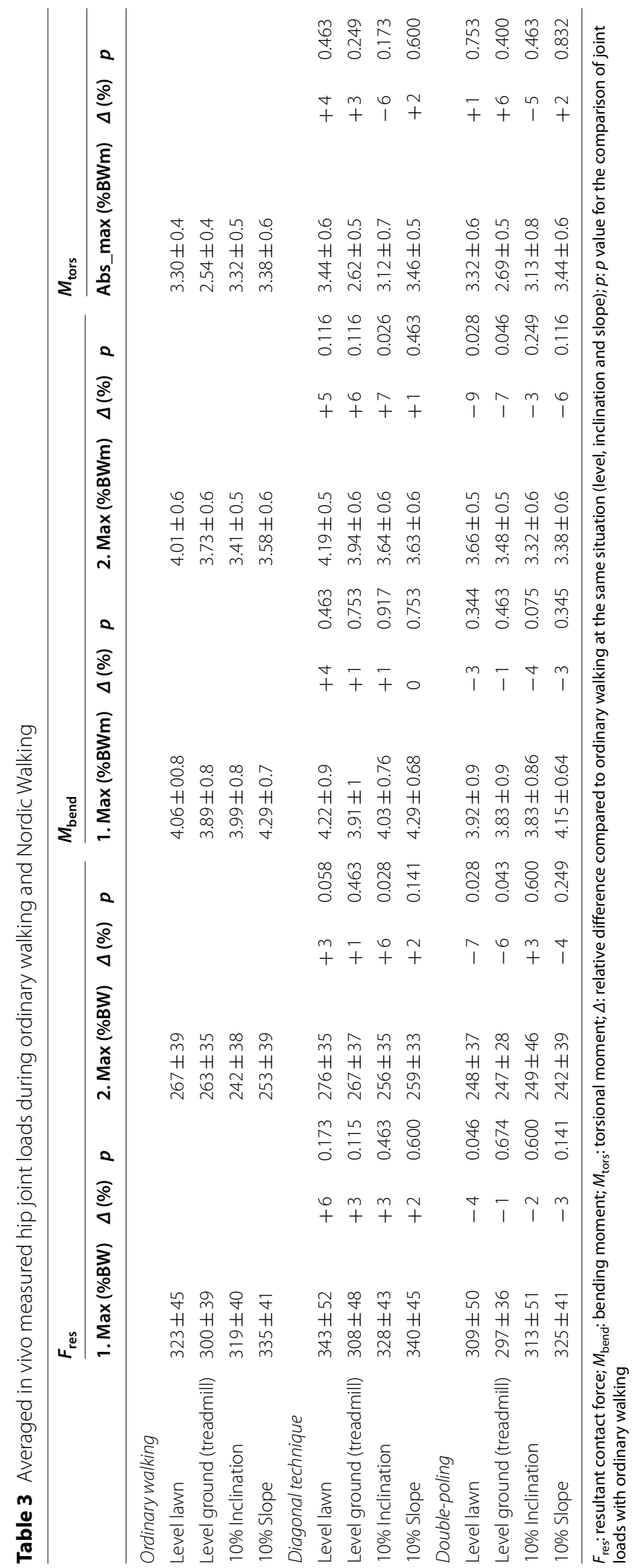


Table 4 Percentual differences in hip joint loads between diagonal technique and double-poling

\begin{tabular}{|c|c|c|c|c|c|c|c|c|c|c|}
\hline & \multicolumn{4}{|l|}{$F_{\text {res }}$} & \multicolumn{4}{|l|}{$M_{\text {bend }}$} & \multirow{2}{*}{\multicolumn{2}{|c|}{$\begin{array}{l}M_{\text {tors }} \\
\text { Absolute } \\
\text { maximum }\end{array}$}} \\
\hline & \multicolumn{2}{|c|}{ 1. Max } & \multicolumn{2}{|c|}{ 2. Max } & \multicolumn{2}{|l|}{ 1. Max } & \multicolumn{2}{|l|}{ 2. Max } & & \\
\hline & $\Delta(\%)$ & $p$ & $\Delta(\%)$ & $p$ & $\Delta(\%)$ & $p$ & $\Delta(\%)$ & $p$ & $\Delta(\%)$ & $p$ \\
\hline Level ground & -4 & 0.141 & -7 & 0.028 & -2 & 0.345 & -12 & 0.028 & -3 & 0.600 \\
\hline $10 \%$ Inclination & -5 & 0.249 & -3 & 0.345 & -5 & 0.046 & -9 & 0.028 & 0 & 0.600 \\
\hline 10\% Slope & -4 & 0.116 & -7 & 0.075 & -3 & 0.172 & -7 & 0.046 & -1 & 0.345 \\
\hline Lawn & -10 & 0.028 & -10 & 0.028 & -7 & 0.116 & -13 & 0.028 & -3 & 0.753 \\
\hline
\end{tabular}

Differences are presented in relation to the values of the diagonal technique. $F_{\text {res }}:$ resultant contact force; $M_{\text {bend }}:$ bending moment; $M_{\text {tors: }}:$ torsional moment

walking velocity was $0.31 \mathrm{~km} / \mathrm{h}(+7.1 \%)$ faster than for normal walking. This might explain the trend towards higher joint loads, as an increase of up to $+6 \%$ should be expected merely due to the higher walking speed [55]. From these results we conclude that NW on a level lawn using the diagonal technique does not relevantly increase hip joint loads. These results are in line with those from two previous studies, that reported either a slight reduction of joint forces or no difference in joint loads for NW on level ground $[36,56]$. One study with 15 patients reported siginificantly higher lower extremity joint loads for NW compared to ordinary walking [57]. However, this study focused on the knee instead of the hip and was performed at a much higher walking speed than our study $(7.2 \mathrm{~km} / \mathrm{h}$ versus $4.4-4.7 \mathrm{~km} / \mathrm{h})$ [57].

Similar to walking on level ground, NW with either technique at $10 \%$ slope or $10 \%$ inclination did not significantly influence hip joint loads in vivo compared to ordinary walking under the same conditions. Our results showed an increase of the second (lower) peak (CHS) for $F_{\text {res }}$ and $M_{\text {bend }}$ at $10 \%$ inclination for the diagonal technique. However, the increases were overall moderate $(\leq+7 \%)$ and hardly affected the absolute peak loads, which occurred at the first maximum for both $F_{\text {res }}$ and $M_{\text {bend }}$ and only showed a trend towards an increase of $\leq+3 \%$. Since the peak loads were hardly influenced by NW, an elevated risk due to NW using the diagonal rechnique after orthopaedic surgery seems rather unlikely. To the best of our knowledge, this is the first study to examine the influence of NW on hip joint forces at inclined surfaces in vivo, so that a comparison to existing studies is difficult. The influence of NW on lower extremity joint forces during walking downhill has been examined by one other study so far, which used 3:1 double-poling at a slope of 25\% [58]. This study reported a reduction of ground reaction forces and calculated knee joint loads of $12-25 \%$ for NW. Although we did not observe a significant reduction of joint forces for NW at 10\% slope, our results confirm that NW does not lead to increased joint loads at $10 \%$ slope and can therefore safely be performed after THA. When comparing the two techniques, double-poling showed overall lower joint loads for both $F_{\text {res }}$ and $M_{\text {bend }}$, ranging up to a difference of $-13 \%$ for $M_{\text {bend }}$ at CHS and $-10 \%$ for $F_{\text {res }}$ at CTO and CHS on a level lawn. $M_{\text {tors }}$ did not significantly differ between the two techniques. These results suggest that in situations where the avoidance of elevated loads is particularly important, e.g. in the early postoperative phase after orthopaedic surgery, double-poling may be preferred over the diagonal technique. However, it needs to be kept in mind that we only examined forces of the ipsilateral leg, which is put onto the ground at the same time as the poles. No conclusion can be drawn regarding the influence of double-poling on the contralateral leg.

Overall, our results show that NW on level ground does not lead to a relevant increase in hip joint forces. Therefore, we suggest that NW can be safely performed on level ground or at moderate inclinations and slopes by any patient who is allowed ordinary walking with the same walking velocity, e.g. during postoperative rehabilitation after THA. The exact time at which full weight bearing is allowed depends on the circumstances of the surgery (e.g. primary THA vs. revision THA) and is usually decided by the surgeon. For routine primary THA, early full weight bearing has been reported to be safe and is becoming increasingly popular, so that NW could already be introduced in early postoperative stages as soon as patients are able to walk comfortably without crutches [59]. This is of particular interest as NW has been shown to be a good stimulus for the circulation through the use of upper body musculature [60]. Despite the resulting increase in energy expenditure, NW has been reported to cause no perceived difference in exertion rate, which may offer a very convenient way to start sports again after surgery or injury [26]. This is supported by the observations in our study as well as in published literature, 
where the patients' self-chosen comfortable walking speed was faster for NW than for ordinary walking [27]. One study even reported NW to be superior to both strength training and home-based exercises for improving function in patients with hip osteoarthritis [61]. Therefore, NW also seems like an ideal option for younger patients that desire a fast return to physical activity after THA. Furthermore, NW has been shown to improve gait asymmetry [62]. Gait asymmetry occurs in patients with lower extremity osteoarthritis, often persists after THA and is suspected to be associated with accelerated implant wear, making its correction an important aim [63-65]. Even though NW seems generally safe, it should be noted that it might still lead to an elevated risk through postoperative disturbances of balance or the increase in walking speed that we observed compared to ordinary walking. A higher walking speed directly increases hip joint loads and might also increase the risk of falls [55]. Therefore, it seems advisable to only recommend NW once patients are able to comfortably walk without crutches and to remind them to carefully consider their walking speed.

Sports that are typically recommended for early postoperative physiotherapy include low-impact activities such as cycling and aquatic exercises [10, 15]. For dynamic aquatic exercises, a previous in vivo study using instrumented implants reported resultant joint forces in the hip joint of $280 \% \mathrm{BW}$ [21]. These values are similar to those we observed for double-poling on a treadmill with level ground, where $F_{\text {res }}$ was $297 \%$ BW. However, joint loads during aquatic exercises could be lowered considerably if only non-weight-bearing or weight-bearing activities were performed, with values of $106-155 \%$ BW. The effect of cycling on hip joint loads has been examined by another study, which reported resultant hip joint forces of $118 \% \mathrm{BW}$ for an ergometer at $110 \mathrm{~W}$ [24]. Consequently, cycling on an ergometer as well aquatic exercises using non-weight-bearing and weight-bearing activities might be more suitable for patients with load reductions, whereas NW and dynamic aquatic exercises seem to be safe as soon as full weight-bearing is allowed.

Despite our efforts for a rigorous methodology, there are some limitations to our study. The patient cohort is rather small with six participants, five of them male. Larger studies with a more equal representation of male and female patients would be desirable to confirm our results, but are be difficult to realize due to the highly complex methodology. For the measurements on a level lawn, walking velocities were not standardized and each patient chose an individual comfortable walking velocity instead. However, the individual walking velocities only differed by up to -0.8 or $+0.9 \mathrm{~km} / \mathrm{h}$ from the respective average. Yet, we would like to underline that the walking speed only differed between the participants during walking on the lawn, while all other measurements were performed at the same fixed walking speed of $4 \mathrm{~km} / \mathrm{h}$ for all participants. Treadmill walking at a defined walking velocity on the other hand may have been unfamiliar for some of the participants. All patients in this study were NW novices. This ensures a good applicability to patients looking for allowed activies after orthopedic surgeries, as the majority of these may not have previous NW experience. However, it is possible that joint loads would differ in a more experienced cohort. We suspect joint loads to rather decrease than increase in such patients, as more experience will likely lead to a more efficient technique. Furthermore, due to the use of instrumented implants for the in vivo load measurements, only patients with previous THA could be included. Even though it seems likely that the effects of NW on joint loads are similar in healthy patient, no definite conclusions can be drawn from our study.

\section{Conclusion}

The study presents for the first time in vivo hip joint loads during NW with two different techniques. These unique in vivo data suggest that NW on level ground and at moderate inclinations or slopes does not relevantly change hip joint loads compared to normal walking at the same conditions. Thus, NW at normal walking speed can be considered a low-impact sport and seems to be a safe postoperative activity for patients that are allowed full weight bearing. However, it should be kept in mind that NW is often performed at a higher walking speed than ordinary walking, which may cause increased joint loads.

\section{Acknowledgements}

This work is based on the master thesis of Simone Schuster at the Julius Wolff Institute. The study was supported by German Research Society (DA 1786/51), the German Federal Ministry of Education and Research (BMBF 01EC1905D, BMBF-workHealth, Subproject 3) and the OrthoLoadClub. Dr. Palmowski is participant in the $\mathrm{BIH}$-Charite Junior Clinician Scientist Program funded by the Charité-Universitätsmedizin Berlin and the Berlin Institute of Health.

\section{Authors' Contributions}

YP participated in the analysis and interpretation of data, drafted the manuscript, approved the submitted version and agrees both to be personally accountable for the author's own contributions and to ensure that questions related to the accuracy or integrity of any part of the work. SP participated in the interpretation of data, critically revised the manuscript, approved the submitted version and agrees both to be personally accountable for the author's own contributions and to ensure that questions related to the accuracy or integrity of any part of the work. SGS participated in the design of the work, acquisition, analysis and interpretation of data, critically revised the manuscript, approved the submitted version and agrees both to be personally accountable for the author's own contributions and to ensure that questions related to the accuracy or integrity of any part of the work. SH participated in the interpretation of data, critically revised the manuscript, approved the submitted version and agrees both to be personally accountable for the author's own contributions and to ensure that questions related to the accuracy or integrity of any part of the work. PD participated in the design of the work, the acquisition, analysis and interpretation of data, substantially revised the work, approved the submitted version and agrees both to be personally 
accountable for the author's own contributions and to ensure that questions related to the accuracy or integrity of any part of the work. All authors read and approved the final manuscript.

\section{Funding}

Open Access funding enabled and organized by Projekt DEAL. This work was supported by German Research Society (DA 1786/5-1)) and the OrthoLoadClub.

\section{Availability of data and materials}

Selected trials of each measurement are published and can be downloaded at the public data base www.OrthoLoad.com.

\section{Declarations}

\section{Ethics approval and consent to participate}

The implantation and the study protocols were approved by the institutional review board of the Charité - Universitätsmedizin Berlin (EA2/057/09) and registered at the 'German Clinical Trials Register' (DRKS00000563). All patients gave written informed consent prior to participation in these studies, in which they agreed to implantation of the instrumented implants, in vivo load measurements and the publication of their images. All methods were performed in accordance with the relevant guidelines and regulations. The funders played no role in the design, conduct, or reporting of this study.

\section{Competing interests}

The authors declare that they have no competing interests.

\section{Author details}

${ }^{1}$ Center for Musculoskeletal Surgery, Charité - Universitätsmedizin Berlin, Corporate Member of Freie Universität Berlin, Humboldt-Universität Zu Berlin, and Berlin Institute of Health, Chariteplatz 1, 10117 Berlin, Germany. ${ }^{2}$ Berlin Institute of Health at Charité - Universitätsmedizin Berlin, Julius Wolff Institute, Augustenburger Platz 1, 13353 Berlin, Germany.

Received: 10 June 2021 Accepted: 21 September 2021

Published online: 14 October 2021

\section{References}

1. Buckwalter JA, Anderson DD, Brown TD, Tochigi Y, Martin JA. The roles of mechanical stresses in the pathogenesis of osteoarthritis: implications for treatment of joint injuries. Cartilage. 2013;4(4):286-94.

2. Dangsheng $X$. Friction and wear properties of UHMWPE composites reinforced with carbon fiber. Mater Lett. 2005;59(2-3):175-9.

3. Mazzucucco D, Spector M. Effects of contact area and stress on the volumetric wear of ultrahigh molecular weight polyethylene. Wear. 2003;254(5-6):514-22.

4. Pietrabissa R, Raimondi M, Di Martino E. Wear of polyethylene cups in total hip arthroplasty: a parametric mathematical model. Med Eng Phys. 1998;20(3):199-210.

5. Seedhom BB, Wallbridge NC. Walking activities and wear of prostheses. Ann Rheum Dis. 1985;44(12):838-43.

6. Shen G, Zhang J, Fang F. In vitro evaluation of artificial joints: a comprehensive review. Adv Manuf. 2019;7(1):1-14.

7. Phillips TW, Nguyen LT, Munro SD. Loosening of cementless femoral stems: a biomechanical analysis of immediate fixation with loading vertical, femur horizontal. J Biomech. 1991;24(1):37-48.

8. Maradit Kremers H, Larson DR, Crowson CS, Kremers WK, Washington $\mathrm{RE}$, Steiner CA, et al. Prevalence of total hip and knee replacement in the United States. J Bone Joint Surg Am. 2015;97(17):1386-97.

9. Learmonth ID, Young C, Rorabeck C. The operation of the century: total hip replacement. Lancet. 2007;370(9597):1508-19.

10. Vu-Han T, Hardt S, Ascherl R, Gwinner C, Perka C. Recommendations for return to sports after total hip arthroplasty are becoming less restrictive as implants improve. Arch Orthop Trauma Surg. 2020;141:497-507.

11. Klug A, Gramlich Y, Hoffmann R, Pfeil J, Drees P, Kutzner KP. Trends in total hip arthroplasty in Germany from 2007 to 2016: What has changed and where are we now? Z Orthop Unfall. 2019;159:173-80.
12. Hoorntje A, Janssen KY, Bolder SBT, Koenraadt KLM, Daams JG, Blankevoort L, et al. The effect of total hip arthroplasty on sports and work participation: a systematic review and meta-analysis. Sports Med. 2018;48(7):1695-726.

13. Crowninshield RD, Rosenberg AG, Sporer SM. Changing demographics of patients with total joint replacement. Clin Orthop Relat Res. 2006;443:266-72.

14. Meek RMD, Treacy R, Manktelow A, Timperley JA, Haddad FS. Sport after total hip arthroplasty: undoubted progress but still some unknowns. Bone Joint J. 2020;102-B(6):661-3.

15. Vogel LA, Carotenuto G, Basti JJ, Levine WN. Physical activity after total joint arthroplasty. Sports Health. 2011;3(5):441-50.

16. Kilgus DJ, Dorey FJ, Finerman GA, Amstutz HC. Patient activity, sports participation, and impact loading on the durability of cemented total hip replacements. Clin Orthop Relat Res. 1991;269:25-31.

17. Huch K, Muller KA, Sturmer T, Brenner H, Puhl W, Gunther KP. Sports activities 5 years after total knee or hip arthroplasty: the UIm osteoarthritis study. Ann Rheum Dis. 2005;64(12):1715-20.

18. Wylde V, Blom A, Dieppe P, Hewlett S, Learmonth I. Return to sport after joint replacement. J Bone Joint Surg Br. 2008;90(7):920-3.

19. Kuster MS. Exercise recommendations after total joint replacement. Sports Med. 2002:32:433-45.

20. Thiele K, Hube R. Hip arthroplasty with increased expectancy. Z Orthop Unfall. 2019;159:91-7.

21. Kutzner I, Richter A, Gordt K, Dymke J, Damm P, Duda GN, et al. Does aquatic exercise reduce hip and knee joint loading In vivo load measurements with instrumented implants. PLoS ONE. 2017;12(3):e0171972.

22. Berry DJ, Bozic KJ. Current practice patterns in primary hip and knee arthroplasty among members of the American Association of Hip and Knee Surgeons. J Arthroplast. 2010;25(6 Suppl):2-4.

23. Cherian JJ, Jauregui JJ, Banerjee S, Pierce T, Mont MA. What host factors affect aseptic loosening after THA and TKA? Clin Orthop Relat Res. 2015;473(8):2700-9.

24. Damm P, Dymke J, Bender A, Duda G, Bergmann G. In vivo hip joint loads and pedal forces during ergometer cycling. J Biomech. 2017;60:197-202.

25. Cebula A, Tyka AK, Tyka A, Palka T, Pilch W, Luty L, et al. Physiological response and cardiorespiratory adaptation after a 6-week Nordic walking training targeted at lipid oxidation in a group of post-menopausal women. PLoS ONE. 2020;15(4):e0230917.

26. Church TS, Earnest CP, Morss GM. Field testing of physiological responses associated with Nordic walking. Res Q Exerc Sport. 2002;73(3):296-300.

27. Willson J, Torry MR, Decker MJ, KernozekT, Steadman JR. Effects of walking poles on lower extremity gait mechanics. Med Sci Sports Exerc. 2001;33(1):142-7.

28. Stief F, Kleindienst Fl, Wiemeyer J, Wedel F, Campe S, Krabbe B. Inverse dynamic analysis of the lower extremities during Nordic walking, walking, and running. J Appl Biomech. 2008;24(4):351-9.

29. Kleindienst FI, Michel KJ, Schwarz J, Krabbe B. Vergleich von kinematischen und kinetischen parameters zwischen den Bewegungsformen Nordic Walking, Walking und Laufen. Sportverletz Sportschaden. 2006;20:25-30.

30. Kleindienst Fl, Stief F, Wedel F, Campe S, Krabbe B. Joint loading of lower extremities during Nordic walking compared to walking based on kinetic and kinematic data. In: Proceedings of the XXIV international symposium on biomechanics in sports. 2006.

31. Kleindienst FI, Michel KJ, Stief F, Wedel F, Campe S, Krabbe B. Vergleich der gelenkbelastung der unteren extremitäten zwischen den bewegungsformen Nordic walking, walking und Laufen mittels inverser dynamik. Dtsch Z Sportmed. 2007;58(4):105-11.

32. Hagen M, Hennig EM, Stieldorf P. Ground reaction forces, rearfoot motion and wrist acceleration in Nordic walking. In: Proceedings of the XXIV international symposium on biomechanics in sports. 2006. pp. 139-42.

33. Thorwesten L, Overhaus N, Rudack P, Völker K. Vergleichende plantare Druckverteilungsmessung beim Nordic Walking und Walking. Deutsche Zeitschrift für Sportmedizin. 2005;56(7/8):215.

34. JöllenbeckT, Leyser D, Classen C, Mull M, Grüneberg C. Biomechanical loading of the lower extremities during Nordic walking — a field study. In: Proceedings of the XXIV international symposium on biomechanics in sports. 2006. pp. 624-7.

35. JöllenbeckT, Leyser D, Classen C, Mull M, Grüneberg C. Nordic walking. Eine feldstudie über den mythos gelenkentlastung. Prävention und 
Rehabilitation. 2007;Symposiumsbericht Bad Sassendorf. 2006. pp. 399-405.

36. Koizumi T, Tsujiuchi N, Takeda M, Fujikura R, Kojima T. Load dynamics of joints in Nordic walking. Procedia Eng. 2011;13:544-51.

37. Delp SL, Anderson FC, Arnold AS, Loan P, Habib A, John CT, et al. OpenSim: open-source software to create and analyze dynamic simulations of movement. IEEE Trans Biomed Eng. 2007;54(11):1940-50.

38. Seth A, Hicks JL, Uchida TK, Habib A, Dembia CL, Dunne JJ, et al. OpenSim: Simulating musculoskeletal dynamics and neuromuscular control to study human and animal movement. PLoS Comput Biol. 2018;14(7):e1006223.

39. Stansfield BW, Nicol AC, Paul JP, Kelly IG, Graichen F, Bergmann G. Direct comparison of calculated hip joint contact forces with those measured using instrumented implants. An evaluation of a three-dimensional mathematical model of the lower limb. J Biomech. 2003;36(7):929-36.

40. Moisio KC, Sumner DR, Shott S, Hurwitz DE. Normalization of joint moments during gait: a comparison of two techniques. J Biomech. 2003;36(4):599-603.

41. Bergmann G, Graichen F, Rohlmann A, Westerhoff P, Bender A, Gabel U, et al. Loads acting on orthopaedic implants. Measurements and practical applications. Orthopade. 2007;36(3):195-6.

42. Bergmann G, Graichen F, Rohlmann A, Westerhoff P, Heinlein B, Bender A, et al. Design and calibration of load sensing orthopaedic implants. J Biomech Eng. 2008;130(2):021009.

43. Damm P, Graichen F, Rohlmann A, Bender A, Bergmann G. Total hip joint prosthesis for in vivo measurement of forces and moments. Med Eng Phys. 2010;32(1):95-100.

44. Damm P, Schwachmeyer V, Dymke J, Bender A, Bergmann G. In vivo hip joint loads during three methods of walking with forearm crutches. Clin Biomech (Bristol, Avon). 2013;28(5):530-5.

45. Bergmann G, Bender A, Dymke J, Duda G, Damm P. Standardized loads acting in hip implants. PLOS ONE. 2016;11(5):e0155612.

46. Angelini L, Damm P, Zander T, Arshad R, Di Puccio F, Schmidt H. Effect of arm swinging on lumbar spine and hip joint forces. J Biomech. 2018;70:185-95.

47. Bergmann G, Bender A, Dymke J, Duda GN, Damm P. Physical activities that cause high friction moments at the cup in hip implants. J Bone Joint Surg Am. 2018;100(19):1637-44.

48. Bergmann G, Kutzner I, Bender A, Dymke J, Trepczynski A, Duda GN, et al. Loading of the hip and knee joints during whole body vibration training. PLOS ONE. 2018;13(12):e0207014.

49. Damm P, Bender A, Duda G, Bergmann G. In vivo measured joint friction in hip implants during walking after a short rest. PLOS ONE. 2017;12(3):e0174788.

50. Damm P, Kutzner I, Bergmann G, Rohlmann A, Schmidt H. Comparison of in vivo measured loads in knee, hip and spinal implants during level walking. J Biomech. 2017;51:128-32.

51. Damm P, Zonneveld J, Brackertz S, Streitparth F, Winkler T. Gluteal muscle damage leads to higher in vivo hip joint loads 3 months after total hip arthroplasty. PLOS ONE. 2018;13(1):e0190626.

52. Damm P, Bender A, Bergmann G. Postoperative changes in in vivo measured friction in total hip joint prosthesis during walking. PLoS ONE. 2015;10(3):e0120438.
53. Graichen F, Arnold R, Rohlmann A, Bergmann G. Implantable 9-channel telemetry system for in vivo load measurements with orthopedic implants. IEEE Trans Biomed Eng. 2007:54(2):253-61.

54. Bender A, Bergmann G. Determination of typical patterns from strongly varying signals. Comput Methods Biomech Biomed Eng. 2012;15(7):761-9.

55. Giarmatzis G, Jonkers I, Wesseling M, Van Rossom S, Verschueren S. Loading of hip measured by hip contact forces at different speeds of walking and running. J Bone Miner Res. 2015;30(8):1431-40.

56. Hansen L, Henriksen M, Larsen P, Alkjaer T. Nordic walking does not reduce the loading of the knee joint. Scand J Med Sci Sports. 2008;18(4):436-41.

57. Kleindienst FI, Stief F, Wedel F, Campe S, Krabbe B. Joint loading of lower extremities during Nordic walking compared to walking based on kinetic and kinematic data 24. In: International symposium on biomechanics in sports 2006.

58. Schwameder H, Roithner R, Muller E, Niessen W, Raschner C. Knee joint forces during downhill walking with hiking poles. J Sports Sci. 1999:17(12):969-78.

59. Tian $P, L i Z J, X u$ GJ, Sun XL, Ma XL. Partial versus early full weight bearing after uncemented total hip arthroplasty: a meta-analysis. J Orthop Surg Res. 2017;12(1):31.

60. Kukkonen-Harjula K, Hiilloskorpi H, Manttari A, Pasanen M, Parkkari J, Suni J, et al. Self-guided brisk walking training with or without poles: a randomized-controlled trial in middle-aged women. Scand J Med Sci Sports. 2007:17(4):316-23.

61. Bieler T, Siersma V, Magnusson SP, Kjaer M, Christensen HE, Beyer N. In hip osteoarthritis, Nordic walking is superior to strength training and home-based exercise for improving function. Scand J Med Sci Sports. 2017;27(8):873-86.

62. Kato N, Fukusaki C, Leetawesup K, Kadokura Y, Ishii N. Improvement in gait asymmetry during Nordic walking in patients with lower extremity osteoarthritis. J Phys Fitness Sports Med. 2020;9(2):65-73.

63. Hodt-Billington C, Helbostad JL, Vervaat W, Rognsvag T, Moe-Nilssen R. Criteria of gait asymmetry in patients with hip osteoarthritis. Physiother Theory Pract. 2012;28(2):134-41.

64. Mendiolagoitia L, Rodriguez MA, Crespo I, Del Valle M, Olmedillas H. Kinematic gait analysis after primary total hip replacement: a systematic review: gait after total hip replacement: a systematic review. Indian J Orthop. 2020;54(6):767-75.

65. Ardestani MM, Amenabar Edwards PP, Wimmer MA. Prediction of polyethylene wear rates from gait biomechanics and implant positioning in total hip replacement. Clin Orthop Relat Res. 2017;475(8):2027-42.

\section{Publisher's Note}

Springer Nature remains neutral with regard to jurisdictional claims in published maps and institutional affiliations.

Ready to submit your research? Choose BMC and benefit from

- fast, convenient online submission

- thorough peer review by experienced researchers in your field

- rapid publication on acceptance

- support for research data, including large and complex data types

- gold Open Access which fosters wider collaboration and increased citations

- maximum visibility for your research: over 100M website views per year

At BMC, research is always in progress.

Learn more biomedcentral.com/submissions 